Cell Mol Life Sci. 2013 October ; 70(19): 3513-3524. doi:10.1007/s00018-012-1256-2.

\title{
The NuRD architecture
}

\author{
Hillary F. Allen ${ }^{1,2}$, Paul A. Wade ${ }^{3}$, and Tatiana G. Kutateladze ${ }^{1,2}$ \\ ${ }^{1}$ Department of Pharmacology, University of Colorado School of Medicine, Aurora, CO 80045, \\ USA
}

${ }^{2}$ Neuroscience Program, University of Colorado School of Medicine, Aurora, CO 80045, USA

${ }^{3}$ Laboratory of Molecular Carcinogenesis, National Institute of Environmental Health Sciences, Research Triangle Park, NC 27709, USA

\begin{abstract}
The nucleosome remodeling and deacetylase (NuRD) complex regulates chromatin organization, gene transcription, genomic stability and developmental signaling. NuRD has a unique dual enzymatic activity, containing an ATPase and a histone deacetylase (HDAC) among its six core subunits. Recent studies indicate that NuRD composition and the interplay between subunits may dictate the diverse functions of the complex. In this review, we examine the structures and biological roles of the NuRD subunits and discuss new avenues of research to advance our understanding of the NuRD-mediated signaling network.
\end{abstract}

\section{Keywords}

NuRD complex; chromatin

\section{Introduction}

The eukaryotic genome is tightly regulated through mechanisms involving chromatin reorganization and the installation or removal of epigenetic marks on DNA and histones. These mechanisms provide accessibility of DNA to nuclear proteins and protein complexes that mediate fundamental DNA-templated processes, including gene transcription and DNA repair, recombination and replication. To date, most known regulatory complexes utilize a single mechanism; however NuRD complex constitutes a notable exception coupling two. NuRD was identified in 1998, and it remains the only chromatin remodeler with ATPase and histone deacetylase functions $1 ; 2 ; 3 ; 4$. One of the catalytic subunits of the complex, CHD3/4 ATPase, utilizes energy derived from hydrolysis of ATP for DNA sliding and repositioning of nucleosomes. The second catalytic subunit, HDAC1/2 (histone deacetylase), deacetylates acetylated lysine residues of histone and non-histone proteins. This dual enzymatic activity is proposed to be important for the efficient formation of heterochromatin with densely packed hypoacetylated nucleosomes and the rapid termination of gene transcription ${ }^{5 ; 6}$. In addition to the catalytic subunits, other components of the complex include the nonenzymatic proteins MBD2/3 (methyl-CpG-binding domain), RBBP7/4 (retinoblastomabinding proteins), MTA1/2/3 (metastasis-associated) and p66a/ß (Fig. 1).

The NuRD complex has a multifaceted biological role. It has been implicated in a wide variety of nuclear processes including gene transcription, DNA damage repair, maintenance of genome stability, and chromatin assembly $5 ; 7$. The subunit composition of the complex 
varies, reflecting alterations in the activity and localization of NuRD and influencing downstream signaling events ${ }^{8}$. NuRD functions can further be modulated through changes in the local epigenetic environment. Aberrant activity of NuRD is associated with human diseases including cancer and aging, and therefore NuRD components represent potential targets for therapeutic interventions ${ }^{7 ; 9}$. In this review, we detail the molecular mechanisms underlying biological activities of each component of the NuRD complex, discuss cross-talk between the subunits, and summarize functional properties of the complex in various biological pathways.

\section{CHD3/4 ATPase}

The human chromodomain helicase DNA-binding protein 3 (CHD3) and CHD4, also known as $\mathrm{Mi}-2 \alpha$ and $\mathrm{Mi}-2 \beta$, respectively, were discovered as autoantigens in an autoimmune disease dermatomyositis ${ }^{10 ; 11}$. CHD3 and CHD4 belong to the class II subfamily of CHD ATPases, and each is present as a core catalytic subunit in separate NuRD complexes. CHD3 and CHD4 are $200 \mathrm{kDa}$ proteins, conserved in vertebrate animals and plants. They contain tandem plant homeodomain fingers (PHDs), two chromodomains (CDs) and an ATPase/helicase module (Fig. 1b). Additionally, two domains of unknown function (DUF) have been identified at the C-terminus of these proteins. The PHD fingers of CHD4 have been shown to recognize histone $\mathrm{H} 3$ tails ${ }^{12}, 13$. The PHD fingers are followed by CDs which bind to DNA ${ }^{14}$, and the SNF2-like ATPase/helicase domain that hydrolyzes ATP, providing the energy necessary for histone displacement and sliding during nucleosome remodeling ${ }^{15}$.

Separated by a short linker, the PHDs of CHD4 associate with nucleosomes in a bivalent manner, concomitantly recognizing two histone $\mathrm{H} 3$ tails $^{16}$. Posttranslational modifications (PTMs) of histone $\mathrm{H} 3$ fine-tune this association in a functionally relevant way. Methylation of Lys9 (H3K9me3) enhances binding of PHDs, whereas methylation of Lys4 (H3K4me3) abolishes it ${ }^{12}$. The synergistic interactions of PHDs displace HP1Y from pericentric sites, inducing changes in chromatin structure and leading to the dispersion of the pericentric heterochromatin mark $\mathrm{H} 3 \mathrm{~K} 9 \mathrm{me} 3{ }^{16}$. The bivalent engagement is also required for the repressive activity of $\mathrm{NuRD}^{16}$. Histone binding of PHDs augments the ATPase and chromatin remodeling functions of CHD4 ${ }^{17}$. Likewise, the ATPase/helicase domain promotes the association of the PHDs/CDs-containing region of CHD4 with histones ${ }^{18}$.

The solution structure of the second PHD2 finger of CHD4 in complex with H3K9me3 peptide provides insight into the molecular mechanism of histone recognition ${ }^{13}$. The PHD2 finger folds into a double-stranded antiparallel $\beta$-sheet and three loops, stabilized by two zinc-binding clusters. The $\mathrm{H} 3 \mathrm{~K} 9 \mathrm{me} 3$ peptide adopts an extended conformation and forms an additional antiparallel $\beta$-strand, pairing with the $\beta$-sheet of the protein (Fig. 2a). Intermolecular hydrogen bonds restrain the $\mathrm{N}$-amino group of Ala1 and the side chain of Lys 4 of the peptide. The trimethylammonium group of Lys9 makes a cation-m contact with a phenylalanine of the PHD2 finger. The structures of the PHD1 and PHD2 fingers of CHD4 in the unbound states superimpose well ${ }^{13 ;}{ }^{19}$, suggesting a similar mode of histone recognition for PHD1.

The NMR structure of the second chromodomain (CD2) of CHD4 shows that it consists of three $\beta$ strands and an $\alpha$ helix (PDB 2EE1, unpublished). Unlike other CDs that recognize methylated histone marks, for example H3K9me3 and H3K27me $3{ }^{20}$, the CHD4 chromodomains do not associate with histone tails and instead bind DNA ${ }^{14}$. It has been proposed that interaction with DNA facilitates the movement of CHD4 along DNA, since higher rates of ATP hydrolysis are observed for the ATPase/helicase domain linked to CDs as compared to the activity of the ATPase/helicase domain alone ${ }^{17}$. Both CDs are necessary for the repressive activity of $\mathrm{NuRD}^{21}$. 
Small-angle X-ray scattering (SAXS) studies reveal intricate contacts within the individual domains of CHD4 and suggest the existence of regulatory mechanisms ${ }^{17}$; 18 . In the SAXS models, CDs interact robustly with the ATPase/helicase domain and additional contacts are seen between the ATPase/helicase domain and DUF1, between CDs and DUF1, and between PHDs and CDs. The PHDs-CDs interaction is found to limit the association of CHD4 with nucleosomes ${ }^{17}$. As suggested by Morra et al., PHDs can modulate binding of CDs to DNA ${ }^{18}$. Particularly, an acidic linker between the PHD fingers can mask one of the DNA-binding sites of the CDs, precluding the necessary interaction with the DNA ${ }^{18}$.

A considerable interface formed between CDs and the ATPase/helicase domain suggests another regulatory mechanism, in which the ATP- or DNA-binding sites in the inactive ATPase/helicase domain are sterically blocked by $\mathrm{CDs}^{17 ; 18}$. A structural rearrangement in CHD4 in which PHDs and CDs release the ATPase/helicase domain, allowing access to ATP or DNA, would then stimulate the enzymatic activity ${ }^{17}$. These results are in line with the reports on autoinhibition of the ATPase motor by CDs in the homologous protein CHD ${ }^{22}$. The crystal structure of CHD1 demonstrates that an acidic helix connecting two CDs packs against the DNA-binding surface in both lobes of the ATPase motor, regulating access to the motor and allowing CHD1 to distinguish between nucleosomes and naked $\mathrm{DNA}^{22}$.

The C-terminal region of CHD3/4, containing at least two DUFs, possesses repressive transcriptional activity. CHD3 and/or CHD4 from different species have been shown to associate with a number of co-repressors through this region. Interaction with hunchback, Tramtrack69, KAP1, NAB2 and RFP facilitates NuRD recruitment to genomic sites which are down-regulated by these co-repressors $23 ; 24 ; 25 ; 26 ; 27$. Other reported ligands of CHD3/4 include the E7 oncoprotein, the nuclear receptor RORY, Ikaros, and proteins of unknown function Ki-1/57 and CGI-55 28;29;30;31. Additionally, CHD3/4 is in direct contact with HDAC1 $4 ; 25$, and thus represents a hub molecule that mediates multiple interactions of $\mathrm{NuRD}$. It is involved in the inter-subunit assembly, bridging the HDAC1 subunit, as well as in the association with histone $\mathrm{H} 3$ and DNA and in tethering non-NuRD proteins to the complex. It may also link these functions to its catalytic ATPase activity.

\section{HDAC1/2}

The first histone deacetylase, HDAC1, was purified from cow protein extracts in $1996^{32}$. Since then, over a dozen HDACs have been discovered and grouped into three classes (I, II and IV), according to sequence homology, phylogenetic analysis, and catalytic mechanisms ${ }^{33}$. HDAC1 and HDAC2 comprise class I of histone deacetylases (together with HDAC3 and HDAC8). They are conserved in all eukaryotes and are ubiquitously expressed in many tissues. HDAC1/2 catalyzes the removal of the acetyl moiety from the $\epsilon$-amino group of lysine residues in histones and non-histone proteins. In addition to being a major component of the NuRD complex, HDAC1/2 is present in a number of multisubunit complexes, including Sin3A, CoREST, NCoR/SMRT and ES-specific NODE $34 ; 35 ; 36 ; 37$.

HDAC1 and HDAC2 are $~ 50 \mathrm{kDa}$ proteins, which share $85 \%$ sequence identity. They contain a central catalytic deacetylase domain and a C-terminal, slightly more variable tail, which can be posttranslationally modified, i.e. phosphorylated at serine residues, or acetylated, sumoylated and ubiquitinylated at lysine residues ${ }^{38}$. The C-terminal tail may be involved in protein-protein interactions (Fig. 1b) ${ }^{39}$.

The crystal structure of the HDAC2 catalytic domain in complex with a small molecule inhibitor N-(4-aminobiphenyl-3-yl)benzamide shows the characteristic $\alpha / \beta$ deacetylase fold ${ }^{40 ; 41}$. It contains an eight-stranded parallel $\beta$-sheet, sandwiched between 17 a-helices (Fig. 2b). The active site of HDAC2 consists of a deep, narrow, lipophilic pocket or a "tube" 
and an internal cavity immediately adjacent to the tube. Hydrophobic and aromatic residues line up the walls of the tube and the cavity. The zinc ion is positioned at the bottom of the tube and is chelated by two aspartate residues and a histidine. The zinc ion is required for catalysis, in which the carbonyl of an acetyllysine substrate, polarized by zinc coordination, facilitates the general base-promoted nucleophilic attack of a water molecule ${ }^{24}$. The structure of the benzamide-bound HDAC2 provides invaluable information for the design of new generation of HDAC inhibitors because the biphenyl derivative occupies not only the tube, but also partially the internal cavity ${ }^{40}$.

\section{MBD2/3}

MBD2 and MBD3 are members of the methyl cytosine-guanosine (CpG)-binding domain (MBD) family of proteins ${ }^{42 ;} 43$. Of the five MBD members, only MBD2 and MBD3 associate with NuRD and are required for the complex formation and gene repression. MBD2 and MBD3 reside within distinct NuRD complexes ${ }^{44}$ and display some differences in their activities. MBD2 binds robustly to methylated DNA ${ }^{45 ; 46}$, whereas binding of mouse MBD3 to methylated DNA is $~ 22$-fold weaker ${ }^{47}$. Both MBD2 and MBD3 associate with hydroxymethylated DNA, albeit weakly, in the $\mu \mathrm{M}$ range ${ }^{47}$. MBD3 is the smallest subunit of NuRD (30 kDa), and MBD2 is $\sim 40 \mathrm{kDa}$. MBD2 contains the N-terminal glycine-arginine repeats (GR), MBD, a transcriptional repression domain (TRD), and a C-terminal coiled-coil motif (Fig. 1b). Although the role of GR is unclear, binding of MBD to cytosine (methylated at position 5) within a $\mathrm{CpG}$ dinucleotide (mCpG) is well documented $45 ; 46 ; 48 ; 49$. TRD of Drosophila MBD2 is involved in the interaction with p55, a Drosophila homolog of RBBP7/4 ${ }^{50}$. The coiled-coil motif associates with p66a (see p66a below) ${ }^{51 ; 52}$. MBD3 consists of an MBD domain that binds to methylated DNA with a low affinity, a coiled-coil motif, and a C-terminal poly-glutamate (E) region (Fig. 1b).

The structure of MBD from chicken MBD2 bound to a $10 \mathrm{bp}$ DNA fragment, derived from the $\rho$-globin promoter and containing a $\mathrm{mCpG}$ sequence, has been determined by NMR spectroscopy ${ }^{53}$. The MBD module consists of a four-stranded $\beta$-sheet and an a-helix (Fig. $2 \mathrm{c})$. The finger-like loop between $\beta 2$ and $\beta 3$ strands extends into the major groove of DNA. The structure shows that MBD selectively recognizes $\mathrm{mCpG}$ through conserved Arg and Tyr residues that make base-specific interactions with the DNA. Two Arg residues, Arg24 and Arg46, form hydrogen bonds with symmetrically related guanine bases (Gua106 and Gua116), which allow for the aliphatic side chain of each arginine to pack against the methyl groups of mCyt 105 and mCyt 115 . The aromatic side chain of Tyr36 interacts with the methyl group of mCyt105. Unlike other MBDs, the MBD2 MBD module binds its target methylated DNA sequence robustly and in a single orientation. A substantial enhancement in both specificity and affinity is achieved through recognition of the base pairs immediately flanking $\mathrm{mCpG}$, particularly the following guanine. NMR relaxation studies demonstrate that DNA binding stabilizes the DNA-contacting regions, i.e the central $\beta$ sheet and the finger-like loop, whereas the $\mathrm{N}$ - and $\mathrm{C}$-terminal parts of MBD undergo internal dynamic motions ${ }^{53}$.

MBD2 has been shown to associate with HDAC1/2 and MTA2 and target NuRD to a set of genes $^{43 ;} 54$ It also interacts with MIZF ${ }^{55}$, focal adhesion kinase $(\mathrm{FAK})^{56}$, and can form heterodimers with MBD3 57 ; 58 . MBD3 binds HDAC1, MTA2 and RBB7/4 43; 48 . Taken together, MBD2/3 has been proposed to mediate gene silencing by recruiting NuRD and associating macromolecules to the sites of methylated DNA.

\section{RBBP7/4}

The retinoblastoma-binding proteins RBBP7 and RBBP4, historically named retinoblastoma-associated proteins $\mathrm{RbAp} 46$ and $\mathrm{RbAp} 48$, were isolated through their 
interaction with the $\mathrm{Rb}$ tumor suppressor ${ }^{59}$. These proteins act as histone chaperones and associate with various chromatin-remodeling and chromatin-modifying complexes, including Sin3A, PRC2 and NuRD. The amino acid sequences of RBBP7 and RBBP4 are 92\% identical, and although occasionally these proteins impart distinct functions, they both can be found as core subunits of the NuRD complexes.

RBBP7/4 are $\sim 50 \mathrm{kDa}$ proteins composed of a central module, the WD40 repeat, flanked by short N-terminal and C-terminal helices (Fig. 1b). The WD40 repeat binds to the first ahelix of histone $\mathrm{H}_{4}{ }^{60}$ and to the N-terminal region of the GATA- 1 cofactor FOG- ${ }^{61}$. The crystal structures of RBBP7 and RBBP4 show that the WD40 repeat has a seven-bladed $\beta$ propeller architecture and utilizes different sides for intra- and intermolecular interactions (Fig. 3a, b) ${ }^{60 ; 61}$. The N-terminal and C-terminal helices of RBBP7/4 are packed against the first and seventh blades of the propeller. The a-helix of histone $\mathrm{H} 4$ is bound between the $\mathrm{N}$ terminal a-helix and an extended loop, a so-called PP loop, of RBBP7 blade six (Fig. 3a) ${ }^{60}$. Binding is driven primarily by electrostatic interactions between the negatively charged residues of the PP loop and $\operatorname{Arg} 36, \operatorname{Arg} 39$ and $\operatorname{Arg} 40$ of H4, as well as hydrophobic contacts between the hydrophobic residues of the N-terminal a-helix and Ile34 and Leu37 of H4. Notably, in the RBBP7-H4 complex, histone H4 is in the conformation, which differs from its conformation in an intact nucleosome ${ }^{60}$. The authors propose that in the context of chromatin, histone $\mathrm{H} 4$ undergoes conformational changes or unfolding to be accessible to RBBP7. This interaction may be essential in the processes of ATP-dependent chromatin remodeling and nucleosome assembly and disassembly.

The FOG-1-binding site of RBBP4 has no overlap with the H4-biding site of RBBP7. The FOG-1 peptide lies across the top of the $\beta$-propeller (Fig. 3b) ${ }^{61}$. Several loops connecting the propeller blades create a highly acidic surface, which accommodates $13 \mathrm{~N}$-terminal residues of FOG-1. The positively charged Arg3, Arg4 and Lys5 residues of the FOG-1 peptide are particularly involved in the interaction and form hydrogen bonds and salt bridges with four glutamic residues and two asparagines of RBBP4. The side chain of Arg4 inserts deeply into the axial channel of the $\beta$-propeller and makes a cation- $\pi$ interaction with a tyrosine. The RRKQXXP motif of FOG-1 is present in other co-repressors and transcription factors, including BCL11A/B and SALL1, and these proteins may associate with RBBP4 in a similar manner ${ }^{61}$. Indeed, BCL11B interacts directly with RBBP7/4 and aids in the recruitment of NuRD to promoters of its target genes ${ }^{38}$. All of the FOG-1-binding residues in RBBP4 are conserved in RBBP7, implying that both proteins recognize FOG-1, which is in line with the results observed in IP assays ${ }^{62}$. Furthermore, RBBP7/4 has been reported to bind a tumor suppressor BRCA1 and another subunit of NuRD, MTA1 ${ }^{61 ; 63}$. Thus, RBBP7/4 is involved in the NuRD assembly, the association with histone $\mathrm{H} 4$ when it is accessible, and can also link non-core proteins to the complex.

\section{MTA1/2/3}

Metastasis-associated gene (MTA) proteins comprise a family of ubiquitously expressed coregulators. MTA1 was initially characterized as a gene involved in breast cancer invasion and metastasis ${ }^{64}$. Overexpression of $M T A 1$ is considered to be a hallmark of many carcinomas, and a high level of MTA1 has been shown to correlate with the invasive growth and poor prognosis. MTA1 and two other members, MTA2 and MTA3, are found in mutually exclusive NuRD complexes, which interact with distinct cofactors and are implicated in different signaling pathways ${ }^{3}$. MTAs are $~ 70-80 \mathrm{kDa}$ proteins that share four conserved modules: a bromo adjacent homology (BAH) domain, an ELM2 domain, SANT, and a GATA-zinc finger (GATA-ZnF) (Fig 1b). Although neither of the MTA domains has yet been characterized structurally, the overall scaffolds of the BAH, SANT and the GATA- 
$\mathrm{ZnF}$ domains are known. The structure and function of the ELM2 domain remains undefined; however it is postulated to have DNA- or protein-binding capabilities.

A typical BAH domain consists of several $\beta$-strands and $\alpha$-helices and is involved in protein-protein interactions, including binding to nucleosomes ${ }^{65}$. SANT domains form a compact 3-helix bundle, which can associate with DNA or histones ${ }^{66}$. The GATA-ZnF domain has one or two small double stranded antiparallel $\beta$-sheets and an a-helix, which are connected by a zinc-binding cluster. GATA-Zn recognizes the T/AGATAA/G sequence of DNA but can also recruit proteins ${ }^{67}$. MTA proteins have been shown to interact directly with transcriptional repressors BCL-6 and BCL11B, as well as with the oestrogen receptor a and its coregulators NRIF3, MAT1, MICoA and LMO4, and FOG-1, though it remains undetermined which domains of MTAs mediate these interactions $61 ; 68 ; 69 ; 70 ; 71 ; 72 ; 73 ; 74$.

\section{$\mathrm{p} 66 \alpha / \beta$}

The transcriptional repressor proteins p66a and p66 3 (human paralogs GATAD2A (GATA zinc finger domain containing D2A) and GATAD2B, respectively) comprise the sixth core component of the NuRD complex ${ }^{42}$. p66a and p66 $\beta$ are highly conserved throughout evolution and share a high degree of sequence similarity. They are $68 \mathrm{kDa}$ and $66 \mathrm{kDa}$ in size and contain at least two conserved regions ${ }^{75}$. The first conserved region (CR1) encompasses $\sim 40$ residues (amino acids 137-178 of p66a) in the N-terminal part of the protein ${ }^{75}$. CR1 folds into an a-helix and binds directly to the C-terminal a-helix (CC) of MBD2 ${ }^{51}$. The N-terminal part has also been implicated in the interactions with other components of NuRD. The C-terminal (CR2) region includes a GATA-Zn finger and is involved in binding to unmodified histone tails ${ }^{51}$.

The solution structure of the p66a-MBD2 complex shows a canonical arrangement of two a-helices (Fig. 3c) ${ }^{52}$. The a-helices form an anti-parallel coiled-coil with unique ionic and hydrogen bonding interactions imparting specificity. The 'knobs' made of the bulky hydrophobic side chains of Ile, Val, and Leu of each a-helix fit into 'holes' in the opposing a-helix. Arg and Lys residues surrounding the hydrophobic core create ion pairs and hydrogen bonds with oppositely charged Glu and Asp residues in another coil.

The CR1 region is also implicated in binding to MBD3, MTA2, HDAC1/2 and RBBP7/4 ${ }^{76}$. Both p66a and p66 $\beta$ can be posttranslationally modified by SUMOylation ${ }^{76}$. Two SUMO sites in p66a (Lys30 and Lys487) and a single site in p66 (Lys33) have been identified. The association of p66a with HDAC1 depends on SUMOylation at Lys30, whereas SUMOylation of p66 $\beta$ at Lys33 is necessary for binding to RBBP7 76 .

\section{NuRD complex and gene regulation-a changing of the guard?}

The NuRD complex was initially uncovered in effort to identify histone-modifying enzymes. It was a surprising discovery that a single protein complex couples two distinct enzymatic functions - histone deacetylation and ATP-dependent chromatin remodeling. Based on predominant views at the time, a prevalent model predicted that NuRD would play a role in gene repression ${ }^{77}$. Further, it was largely thought that local genomic enrichment of NuRD would result from protein-DNA interactions (mediated by the MBD2/3 subunit interacting with methylated DNA) or by protein-protein interactions between the complex and transcriptional repressors.

Progress on testing the various predictions of this model was initially slow. Genetic model systems for in vivo functional analysis did not emerge rapidly; and biochemical and molecular tools took time to develop. Testing of the model required definition of target loci subject to regulation by NuRD. Thus, the earliest studies on NuRD function were grounded 
in candidate approaches, where existing biological and expression data were interpreted as indication of a fundamental role for NuRD. Kumar and colleagues hypothesized that MTA1, a NuRD subunit known to be overexpressed in certain breast cancer cell lines ${ }^{64}$, might be a major player in the transcriptional program of these cells. The authors went on to demonstrate that activation of the HER2 signaling pathway in breast cancer cells led to upregulation of MTA1, which was shown to directly interact with the estrogen receptor and repress ER driven transcription ${ }^{78}$. These data provided first direct confirmation of the prevalent models-NuRD was recruited to target genes through direct interaction with a sequence specific transcription factor where it acted to repress transcription.

This finding was echoed by a number of additional studies, which demonstrated that NuRD action opposed gene expression in a relatively static manner. Investigators linked NuRD activities to repression of genes important in breast cancer ${ }^{79}$, prostate cancer ${ }^{26}$, hematopoiesis ${ }^{62 ; 80}$, lymphoma $^{68}$, immunological responses ${ }^{81}$ and $\mathrm{HIV}^{82}$. In most cases, the NuRD complex was recruited through direct or indirect contacts of a specific subunit with a DNA binding protein. In at least one instance, local enrichment of NuRD was directed through interaction of MBD2 with methylated $\mathrm{DNA}^{52}$. The preponderance of evidence derived from candidate approaches, which largely flowed from the prevailing model, suggested that NuRD plays a critical role in gene silencing in a broad variety of biological contexts downstream of multiple, diverse signaling pathways.

Further evidence linking NuRD to silent chromatin states came through biochemical analyses performed with histone peptides. It was observed in two independent reports that NuRD complex could be enriched through binding to the histone $\mathrm{H} 3$ amino terminus. Further, this interaction was abrogated when the peptides were trimethylated at Lys 4 , a chromatin mark associated with gene activity $83 ; 84$. These findings suggested that NuRD targeting to genomic regions is more complicated, and might be influenced by interactions with DNA binding proteins or histones.

Initial inklings that these models could not explain all the biology relevant to NuRD complex came with the emergence of genetic systems. Georgopoulos and colleagues created a conditional mouse model in which the ATPase subunit CHD4 could be deleted in a cell type specific manner. They studied the role of NuRD in T lymphocyte development, finding a genetic requirement at several steps. Importantly, they also observed that CHD4 function was required for expression of the CD4 gene, where NuRD complex was noted to be present at an active enhancer ${ }^{85}$. This same group went on to utilize their genetic model to assess the requirement for CHD4 function in hematopoietic stem cells and their derivatives. NuRD function was found to be essential for the maintenance of stem cell populations; mutant cells skew their differentiation towards the erythroid lineage at the expense of lymphoid and myeloid cells. Notably, global gene expression analysis revealed that loss of CHD4 resulted in roughly equivalent numbers of downregulated and upregulated genes - implicating NuRD in both maintenance and repression of transcription ${ }^{86}$.

A very recent spate of studies using murine embryonic stem cells has also indicated that NuRD function is more complicated than previous models predicted. MBD3 was demonstrated to be essential for differentiation, but not for maintenance of mouse ES cells ${ }^{87}$. Using a genetic system in ES cells permitting conditional rescue of the MBD3 null state, Hendrich and colleagues proposed a model in which NuRD is recruited to active genes required for pluripotency, where it helps to maintain a balance between acetylation and deacetylation of histones, permitting fine-tuning of gene expression. Loss of activating signals leads to an imbalance in which NuRD-mediated deacetylation is integral to decreased expression of the core pluripotency network; in the absence of functional NuRD complex, differentiation does not occur ${ }^{88}$. In parallel, Young and colleagues used genomic 
techniques to map NuRD occupancy across the ES cell genome, concluding that CHD4 is present at many active enhancers in these cells. Presumably NuRD activity is critical for maintaining equilibrium between the acetylated and deacetylated state of histone amino termini. Importantly, NuRD-dependent histone deacetylation was required prior to demethylation of Lys4 of histone H3 by the LSD1 histone demethylase, an act critical to down regulation of enhancer function associated with ES cell differentiation ${ }^{89}$. Finally, an interesting study from the Fazzio and Rando groups suggested an important new determinant of NuRD complex localization in the murine ES cell system. They observed localization of NuRD at core promoters that was abolished by depletion of TET1, an enzyme responsible for generation of 5-hydroxymethyl cytosine. Biochemical analysis with recombinant proteins suggested that mouse MBD3 could specifically bind to DNA fragments containing this modified form of cytosine ${ }^{90}$.

These observations strongly suggest that the initial models depicting NuRD as a static reinforcer of the silent state cannot explain all the biological requirements for NuRD revealed by genetic and genomic analysis. Rather, it seems more likely that transcriptional states reflect dynamic equilibrium between gene activity and repression mediated by modification status of the histone amino termini and by nucleosome positioning - chromatin properties influenced by the catalytic activities of NuRD complex. Along these lines, classic biochemical analysis of histone acetylation indicates that this modification turns over with very rapid kinetics in the active fraction of the genome ${ }^{91 ; 92}$. An emerging model ${ }^{93}$ suggests that active genes utilize NuRD in a dynamic manner to promote turnover of acetyl groups at enhancers and possibly at promoters, an action that results in fine-tuning of gene expression (Fig. 4). Down-regulation results upon loss of activating signals with concurrent decreased local concentration of transcriptional activators and coactivators - molecules that provide enzymatic functions opposing NuRD action. Whether NuRD complex persists and reinforces a silent state once activating signals are removed remains an open question. Likewise, a requirement for ATP-dependent chromatin remodeling in this process has not been demonstrated. It should be emphasized that the data suggesting a dynamic model for $\mathrm{NuRD}$ function are very new and need to be further examined ${ }^{93}$. Nonetheless, the vast preponderance of genetic and genomic data suggests it is time to rethink models explaining $\mathrm{NuRD}$ function in relation to gene expression.

\section{NuRD function in other contexts}

The NuRD complex has recently been implicated in the DNA damage response in several systems. Genetic analyses in C. elegans and mice implicate egrl and its mammalian homolog, MTA1, in the response to ionizing radiation ${ }^{94 ; 95}$. Biochemically, depletion of NuRD subunits leads to hypersensitivity to DNA damage and the accumulation of unrepaired break sites ${ }^{94 ; 96 ; 97 ; 98}$. NuRD complex rapidly accumulates in cells at sites of double-strand breaks in a manner dependent on the activity of poly(ADP ribose) polymerase, PARP ${ }^{96 ; 98}$. These data suggest that protein modification at sites of DNA damage is integral to local NuRD recruitment. Precisely what function(s) NuRD plays in DNA damage repair is currently unclear although its action seems to be required for appropriate accumulation of repair proteins including BRCA1 ${ }^{94 ; 98}$.

$\mathrm{NuRD}$ is also essential in assembly and maintenance of higher order chromosome structures. In rapidly proliferating lymphoid cells, NuRD complex forms an unusual structure, termed a NuRD body, at pericentric heterochromatin on human chromosomes 1, 9 and $16^{99}$. These structures are most abundant in S phase of the cell cycle where they colocalize with sites of active DNA synthesis and chromatin assembly. Perturbation of the central ATPase, CHD4, leads to formation of aberrant structures, loss of localization of characteristic patterns of histone modification (trimethylation of Lys9 on histone H3), and failure of HP1 isoforms to 
concentrate at these regions ${ }^{100}$. Such cells have defects in progression through $\mathrm{S}$ phase, implicating NuRD in some aspect of completion of chromatin assembly in mitotic cells. Overexpression of the tandem PHD fingers of CHD4 mimics many of the actions of CHD4 depletion, including gross structural defects at pericentric heterochromatin ${ }^{16}$, leading to the conclusion that binding of this domain to modified histone tails plays a fundamental role in guiding $\mathrm{NuRD}$ to appropriate sites for assembly of higher order chromatin structures during S phase.

Along these lines, the Drosophila homolog of CHD4, dMi-2, is required for proper higher order chromatin structure. Loss of function alleles of $\mathrm{dMi}-2$ in larvae result in gross structural defects in polytene chromosomes. Interestingly, loss of dMi-2 is associated with an increase in condensation of these structures while overexpression is associated with a loss of condensation and an increase in nuclear volume ${ }^{101}$. Live imaging demonstrated that $\mathrm{dMi}-2$ modulates the interaction of cohesin with chromosomes, providing molecular insights into the observed structural defects.

These recent findings suggest that NuRD action is not strictly limited to gene regulation. It impacts multiple fundamental chromatin-related processes from local histone modification properties to the global folding of chromosomes. In the future, the application of new tools emerging from the exciting structural analysis of NuRD subunits and their functional domains promises to revolutionize how we think about the functions of this enzyme in chromosome biology.

\section{Association with disease}

The catalytic ATPase subunits of NuRD, CHD3 and CHD4, were identified as autoantigens in a class of idiopathic inflammatory myopathies ${ }^{102}$, dermatomyositis, where the autoantigen was termed Mi-2. Autoantibodies against Mi-2 are associated with a very characteristic clinical presentation including specific types of skin lesions. Patients with Mi-2 autoantibodies tend to have a more favorable prognosis, respond to steroid therapy, and have a lower incidence of cancer when compared to other dermatomyositis patients ${ }^{102}$. As CHD3 and CHD4 are nuclear proteins, it is likely that autoantibodies to these species are a marker of disease, rather than drivers of pathology.

The CHD3/4 proteins are expressed at higher levels in muscle tissue collected from dermatomyositis patients than from control subjects ${ }^{103}$. In these patients, elevated expression of Mi-2 is primarily localized to nuclei within myofibers exhibiting perifascicular atrophy or features of myofiber regeneration. In an experimental system of muscle injury and regeneration, Mi-2 expression increased dramatically following muscle injury and remained elevated for up to 12 days ${ }^{104}$. Further study in a cell culture model of muscle differentiation revealed high level expression of Mi-2 in myoblasts which declines as these cells are differentiated. Depletion of Mi-2 by RNA interference led to accelerated differentiation ${ }^{104}$. These findings, prompted by the utility of Mi- 2 autoantibodies as a clinical marker of disease, suggest that Mi-2 protein(s) are expressed at high levels in immature and/or regenerating muscle nuclei where they may play a role in regulating differentiation.

NuRD action is linked to both cancer and to aging. Connections of NuRD to cancer have been recently reviewed ${ }^{7}$ and will not be considered in detail here. In a landmark report, Misteli and colleagues ${ }^{105}$ took advantage of the unique properties of cells derived from patients with the premature aging disorder Hutchinson-Gilford Progeria syndrome to probe the intersection of NuRD with aging. The authors observed that patient-derived cells were characterized by decreased expression of multiple NuRD subunits, concurrent with accumulation of defects in higher order chromatin structures - particularly at pericentric 
heterochromatin. Depletion of these same NuRD subunits in primary fibroblasts elicited responses similar to the defects observed in HGPS. Comparison of primary cells from young versus elderly subjects confirmed that NuRD subunit abundance decreased during normal aging. These results suggest that NuRD function declines with age, perhaps contributing to the chromosomal defects that accumulate with age.

\section{Concluding Remarks}

Over the past decade NuRD-mediated signaling pathways have been studied extensively and some of the NuRD components have been examined in detail. It becomes increasingly clear that the activity of NuRD depends on the precise composition of the complex as well as on the interactions of individual subunits with various non-NuRD partners. Although we have begun gathering information on the structures of domains within the individual subunits, the overall mechanism by which all subunits interact with their ligands and are assembled into the complex and recruited to specific genomic sites remain unclear. The intermingled action of and cross-talk between subunits not only enhance the overall affinity of the complex, but can also provide a high degree of specificity for a particular gene locus. Furthermore, combinatorial assembly of various paralogs of each subunit represents an additional mechanism for altering the chromatin-targeting capability of NuRD. Many uncertainties remain in understanding the biology of NuRD: old models are no longer adequate to explain all the data, and it has become apparent that NuRD is not strictly devoted to a single task. The continued accumulation of structural, biochemical and cell biology data will no doubt drive the generation of new tools and hypotheses to investigate the biological function of this imperative regulator of chromosomes.

\section{Acknowledgments}

The authors apologize to our many colleagues whose work could not be cited here due to space constraints. This work was supported by the NIH grant, GM096863 to T.G.K. This work was supported, in part, by the Intramural Research Program of the US National Institute of Environmental Health Sciences, NIH (Project Number Z01ES101965 to P.A.W.). H.F.A. is supported by the Neuroscience Graduate training grant, T32HD041697.

\section{References}

1. Tong JK, Hassig CA, Schnitzler GR, Kingston RE, Schreiber SL. Chromatin deacetylation by an ATP-dependent nucleosome remodelling complex. Nature. 1998; 395:917-21. [PubMed: 9804427]

2. Wade PA, Jones PL, Vermaak D, Wolffe AP. A multiple subunit Mi-2 histone deacetylase from Xenopus laevis cofractionates with an associated Snf2 superfamily ATPase. Curr Biol. 1998; 8:843-6. [PubMed: 9663395]

3. Xue Y, Wong J, Moreno GT, Young MK, Cote J, Wang W. NURD, a novel complex with both ATP-dependent chromatin-remodeling and histone deacetylase activities. Mol Cell. 1998; 2:851-61. [PubMed: 9885572]

4. Zhang Y, LeRoy G, Seelig HP, Lane WS, Reinberg D. The dermatomyositis-specific autoantigen $\mathrm{Mi} 2$ is a component of a complex containing histone deacetylase and nucleosome remodeling activities. Cell. 1998; 95:279-89. [PubMed: 9790534]

5. Denslow SA, Wade PA. The human Mi-2/NuRD complex and gene regulation. Oncogene. 2007; 26:5433-8. [PubMed: 17694084]

6. Wang HB, Zhang Y. Mi2, an auto-antigen for dermatomyositis, is an ATP-dependent nucleosome remodeling factor. Nucleic Acids Res. 2001; 29:2517-21. [PubMed: 11410659]

7. Lai AY, Wade PA. Cancer biology and NuRD: a multifaceted chromatin remodelling complex. Nat Rev Cancer. 2011; 11:588-96. [PubMed: 21734722]

8. Bowen NJ, Fujita N, Kajita M, Wade PA. Mi-2/NuRD: multiple complexes for many purposes. Biochim Biophys Acta. 2004; 1677:52-7. [PubMed: 15020045] 
9. Pegoraro G, Misteli T. The central role of chromatin maintenance in aging. Aging (Albany NY). 2009; 1:1017-22. [PubMed: 20157584]

10. Ge Q, Nilasena DS, O'Brien CA, Frank MB, Targoff IN. Molecular analysis of a major antigenic region of the 240-kD protein of Mi-2 autoantigen. J Clin Invest. 1995; 96:1730-7. [PubMed: 7560064]

11. Seelig HP, Moosbrugger I, Ehrfeld H, Fink T, Renz M, Genth E. The major dermatomyositisspecific Mi-2 autoantigen is a presumed helicase involved in transcriptional activation. Arthritis Rheum. 1995; 38:1389-99. [PubMed: 7575689]

12. Musselman CA, Mansfield RE, Garske AL, Davrazou F, Kwan AH, Oliver SS, O'Leary H, Denu JM, Mackay JP, Kutateladze TG. Binding of the CHD4 PHD2 finger to histone H3 is modulated by covalent modifications. Biochem J. 2009; 423:179-87. [PubMed: 19624289]

13. Mansfield RE, Musselman CA, Kwan AH, Oliver SS, Garske AL, Davrazou F, Denu JM, Kutateladze TG, Mackay JP. Plant homeodomain (PHD) fingers of CHD4 are histone H3-binding modules with preference for unmodified $\mathrm{H} 3 \mathrm{~K} 4$ and methylated $\mathrm{H} 3 \mathrm{~K} 9$. The Journal of Biological Chemistry. 2011; 286:11779-91. [PubMed: 21278251]

14. Bouazoune K, Mitterweger A, Langst G, Imhof A, Akhtar A, Becker PB, Brehm A. The dMi-2 chromodomains are DNA binding modules important for ATP-dependent nucleosome mobilization. Embo J. 2002; 21:2430-40. [PubMed: 12006495]

15. Hall JA, Georgel PT. CHD proteins: a diverse family with strong ties. Biochem Cell Biol. 2007; 85:463-76. [PubMed: 17713581]

16. Musselman CA, Ramirez J, Sims JK, Mansfield RE, Oliver SS, Denu JM, Mackay JP, Wade PA, Hagman J, Kutateladze TG. Bivalent recognition of nucleosomes by the tandem PHD fingers of the CHD4 ATPase is required for CHD4-mediated repression. Proceedings of the National Academy of Sciences of the United States of America. 2012; 109:787-92. [PubMed: 22215588]

17. Watson AA, Mahajan P, Mertens HD, Deery MJ, Zhang W, Pham P, Du X, Bartke T, Zhang W, Edlich C, Berridge G, Chen Y, Burgess-Brown NA, Kouzarides T, Wiechens N, Owen-Hughes T, Svergun DI, Gileadi O, Laue ED. The PHD and chromo domains regulate the ATPase activity of the human chromatin remodeler CHD4. J Mol Biol. 2012; 422:3-17. [PubMed: 22575888]

18. Morra R, Lee BM, Shaw H, Tuma R, Mancini EJ. Concerted action of the PHD, chromo and motor domains regulates the human chromatin remodelling ATPase CHD4. FEBS Lett. 2012; 586:251321. [PubMed: 22749909]

19. Kwan AHY, Gell DA, Verger A, Grossley M, Matthews JM, Mackay JP. Engineering a protein scaffold from a PHD finger. Structure. 2003; 11:803-13. [PubMed: 12842043]

20. Blus BJ, Wiggins K, Khorasanizadeh S. Epigenetic virtues of chromodomains. Critical reviews in biochemistry and molecular biology. 2011; 46:507-26. [PubMed: 22023491]

21. Ramirez J, Dege C, Kutateladze TG, Hagman J. MBD2 and multiple domains of CHD4 are required for transcriptional repression by Mi-2/NuRD complexes. Mol Cell Biol. 2012

22. Hauk G, McKnight JN, Nodelman IM, Bowman GD. The chromodomains of the Chd 1 chromatin remodeler regulate DNA access to the ATPase motor. Mol Cell. 2010; 39:711-23. [PubMed: 20832723]

23. Kehle J, Beuchle D, Treuheit S, Christen B, Kennison JA, Bienz M, Muller J. dMi-2, a hunchbackinteracting protein that functions in polycomb repression. Science. 1998; 282:1897-900. [PubMed: 9836641]

24. Murawsky CM, Brehm A, Badenhorst P, Lowe N, Becker PB, Travers AA. Tramtrack69 interacts with the dMi-2 subunit of the Drosophila NuRD chromatin remodelling complex. EMBO Rep. 2001; 2:1089-94. [PubMed: 11743021]

25. Shimono Y, Murakami H, Kawai K, Wade PA, Shimokata K, Takahashi M. Mi-2 beta associates with BRG1 and RET finger protein at the distinct regions with transcriptional activating and repressing abilities. J Biol Chem. 2003; 278:51638-45. [PubMed: 14530259]

26. Srinivasan R, Mager GM, Ward RM, Mayer J, Svaren J. NAB2 represses transcription by interacting with the CHD4 subunit of the nucleosome remodeling and deacetylase (NuRD) complex. J Biol Chem. 2006; 281:15129-37. [PubMed: 16574654]

27. Schultz DC, Friedman JR, Rauscher FJ 3rd. Targeting histone deacetylase complexes via KRABzinc finger proteins: the PHD and bromodomains of KAP-1 form a cooperative unit that recruits a 
novel isoform of the Mi-2alpha subunit of NuRD. Genes Dev. 2001; 15:428-43. [PubMed: 11230151]

28. Brehm A, Nielsen SJ, Miska EA, McCance DJ, Reid JL, Bannister AJ, Kouzarides T. The E7 oncoprotein associates with Mi2 and histone deacetylase activity to promote cell growth. EMBO J. 1999; 18:2449-58. [PubMed: 10228159]

29. Johnson DR, Lovett JM, Hirsch M, Xia F, Chen JD. NuRD complex component Mi-2beta binds to and represses RORgamma-mediated transcriptional activation. Biochem Biophys Res Commun. 2004; 318:714-8. [PubMed: 15144897]

30. Lemos TA, Passos DO, Nery FC, Kobarg J. Characterization of a new family of proteins that interact with the C-terminal region of the chromatin-remodeling factor CHD-3. FEBS Lett. 2003; 533:14-20. [PubMed: 12505151]

31. Kim J, Sif S, Jones B, Jackson A, Koipally J, Heller E, Winandy S, Viel A, Sawyer A, Ikeda T, Kingston R, Georgopoulos K. Ikaros DNA-binding proteins direct formation of chromatin remodeling complexes in lymphocytes. Immunity. 1999; 10:345-55. [PubMed: 10204490]

32. Taunton J, Hassig CA, Schreiber SL. A mammalian histone deacetylase related to the yeast transcriptional regulator Rpd3p. Science. 1996; 272:408-11. [PubMed: 8602529]

33. Yang XJ, Seto E. The Rpd3/Hda1 family of lysine deacetylases: from bacteria and yeast to mice and men. Nat Rev Mol Cell Biol. 2008; 9:206-18. [PubMed: 18292778]

34. Zhang Y, Sun ZW, Iratni R, Erdjument-Bromage H, Tempst P, Hampsey M, Reinberg D. SAP30, a novel protein conserved between human and yeast, is a component of a histone deacetylase complex. Mol Cell. 1998; 1:1021-31. [PubMed: 9651585]

35. You A, Tong JK, Grozinger CM, Schreiber SL. CoREST is an integral component of the CoRESThuman histone deacetylase complex. Proc Natl Acad Sci U S A. 2001; 98:1454-8. [PubMed: 11171972]

36. Ordentlich P, Downes M, Xie W, Genin A, Spinner NB, Evans RM. Unique forms of human and mouse nuclear receptor corepressor SMRT. Proc Natl Acad Sci U S A. 1999; 96:2639-44. [PubMed: 10077563]

37. Liang J, Wan M, Zhang Y, Gu P, Xin H, Jung SY, Qin J, Wong J, Cooney AJ, Liu D, Songyang Z. Nanog and Oct4 associate with unique transcriptional repression complexes in embryonic stem cells. Nat Cell Biol. 2008; 10:731-9. [PubMed: 18454139]

38. Segre CV, Chiocca S. Regulating the regulators: the post-translational code of class I HDAC1 and HDAC2. J Biomed Biotechnol. 2011; 2011:690848. [PubMed: 21197454]

39. Thiagalingam S, Cheng KH, Lee HJ, Mineva N, Thiagalingam A, Ponte JF. Histone deacetylases: unique players in shaping the epigenetic histone code. Ann N Y Acad Sci. 2003; 983:84-100. [PubMed: 12724214]

40. Bressi JC, Jennings AJ, Skene R, Wu Y, Melkus R, De Jong R, O’Connell S, Grimshaw CE, Navre M, Gangloff AR. Exploration of the HDAC2 foot pocket: Synthesis and SAR of substituted N-(2aminophenyl)benzamides. Bioorg Med Chem Lett. 2010; 20:3142-5. [PubMed: 20392638]

41. Finnin MS, Donigian JR, Cohen A, Richon VM, Rifkind RA, Marks PA, Breslow R, Pavletich NP. Structures of a histone deacetylase homologue bound to the TSA and SAHA inhibitors. Nature. 1999; 401:188-93. [PubMed: 10490031]

42. Wade PA, Gegonne A, Jones PL, Ballestar E, Aubry F, Wolffe AP. Mi-2 complex couples DNA methylation to chromatin remodelling and histone deacetylation. Nat Genet. 1999; 23:62-6. [PubMed: 10471500]

43. Zhang Y, Ng HH, Erdjument-Bromage H, Tempst P, Bird A, Reinberg D. Analysis of the NuRD subunits reveals a histone deacetylase core complex and a connection with DNA methylation. Genes Dev. 1999; 13:1924-35. [PubMed: 10444591]

44. Le Guezennec X, Vermeulen M, Brinkman AB, Hoeijmakers WA, Cohen A, Lasonder E, Stunnenberg HG. MBD2/NuRD and MBD3/NuRD, two distinct complexes with different biochemical and functional properties. Mol Cell Biol. 2006; 26:843-51. [PubMed: 16428440]

45. Hendrich B, Bird A. Identification and characterization of a family of mammalian methyl-CpG binding proteins. Mol Cell Biol. 1998; 18:6538-47. [PubMed: 9774669]

46. Hendrich B, Tweedie S. The methyl-CpG binding domain and the evolving role of DNA methylation in animals. Trends Genet. 2003; 19:269-77. [PubMed: 12711219] 
47. Hashimoto H, Liu Y, Upadhyay AK, Chang Y, Howerton SB, Vertino PM, Zhang X, Cheng X. Recognition and potential mechanisms for replication and erasure of cytosine hydroxymethylation. Nucleic Acids Res. 2012; 40:4841-9. [PubMed: 22362737]

48. Saito M, Ishikawa F. The mCpG-binding domain of human MBD3 does not bind to $\mathrm{mCpG}$ but interacts with NuRD/Mi2 components HDAC1 and MTA2. J Biol Chem. 2002; 277:35434-9. [PubMed: 12124384]

49. Fraga MF, Ballestar E, Montoya G, Taysavang P, Wade PA, Esteller M. The affinity of different MBD proteins for a specific methylated locus depends on their intrinsic binding properties. Nucleic Acids Res. 2003; 31:1765-74. [PubMed: 12626718]

50. Marhold J, Brehm A, Kramer K. The Drosophila methyl-DNA binding protein MBD2/3 interacts with the NuRD complex via p55 and MI-2. BMC Mol Biol. 2004; 5:20. [PubMed: 15516265]

51. Brackertz M, Gong Z, Leers J, Renkawitz R. p66alpha and p66beta of the Mi-2/NuRD complex mediate MBD2 and histone interaction. Nucleic Acids Res. 2006; 34:397-406. [PubMed: 16415179]

52. Gnanapragasam MN, Scarsdale JN, Amaya ML, Webb HD, Desai MA, Walavalkar NM, Wang SZ, Zu Zhu S, Ginder GD, Williams DC Jr. p66Alpha-MBD2 coiled-coil interaction and recruitment of Mi-2 are critical for globin gene silencing by the MBD2-NuRD complex. Proc Natl Acad Sci U S A. 2011; 108:7487-92. [PubMed: 21490301]

53. Scarsdale JN, Webb HD, Ginder GD, Williams DC Jr. Solution structure and dynamic analysis of chicken MBD2 methyl binding domain bound to a target-methylated DNA sequence. Nucleic Acids Res. 2011; 39:6741-52. [PubMed: 21531701]

54. Ng HH, Zhang Y, Hendrich B, Johnson CA, Turner BM, Erdjument-Bromage H, Tempst P, Reinberg D, Bird A. MBD2 is a transcriptional repressor belonging to the MeCP1 histone deacetylase complex. Nat Genet. 1999; 23:58-61. [PubMed: 10471499]

55. Sekimata M, Takahashi A, Murakami-Sekimata A, Homma Y. Involvement of a novel zinc finger protein, MIZF, in transcriptional repression by interacting with a methyl-CpG-binding protein, MBD2. J Biol Chem. 2001; 276:42632-8. [PubMed: 11553631]

56. Luo SW, Zhang C, Zhang B, Kim CH, Qiu YZ, Du QS, Mei L, Xiong WC. Regulation of heterochromatin remodelling and myogenin expression during muscle differentiation by FAK interaction with MBD2. EMBO J. 2009; 28:2568-82. [PubMed: 19661918]

57. Tatematsu KI, Yamazaki T, Ishikawa F. MBD2-MBD3 complex binds to hemi-methylated DNA and forms a complex containing DNMT1 at the replication foci in late S phase. Genes Cells. 2000; 5:677-88. [PubMed: 10947852]

58. Hendrich B, Guy J, Ramsahoye B, Wilson VA, Bird A. Closely related proteins MBD2 and MBD3 play distinctive but interacting roles in mouse development. Genes Dev. 2001; 15:710-23. [PubMed: 11274056]

59. Qian YW, Wang YC, Hollingsworth RE Jr, Jones D, Ling N, Lee EY. A retinoblastoma-binding protein related to a negative regulator of Ras in yeast. Nature. 1993; 364:648-52. [PubMed: 8350924]

60. Murzina NV, Pei XY, Zhang W, Sparkes M, Vicente-Garcia J, Pratap JV, McLaughlin SH, BenShahar TR, Verreault A, Luisi BF, Laue ED. Structural basis for the recognition of histone H4 by the histone-chaperone RbAp46. Structure. 2008; 16:1077-85. [PubMed: 18571423]

61. Lejon S, Thong SY, Murthy A, AlQarni S, Murzina NV, Blobel GA, Laue ED, Mackay JP. Insights into association of the NuRD complex with FOG-1 from the crystal structure of an RbAp48. FOG-1 complex. J Biol Chem. 2011; 286:1196-203. [PubMed: 21047798]

62. Hong W, Nakazawa M, Chen YY, Kori R, Vakoc CR, Rakowski C, Blobel GA. FOG-1 recruits the NuRD repressor complex to mediate transcriptional repression by GATA-1. EMBO J. 2005; 24:2367-78. [PubMed: 15920470]

63. Yarden RI, Brody LC. BRCA1 interacts with components of the histone deacetylase complex. Proc Natl Acad Sci U S A. 1999; 96:4983-8. [PubMed: 10220405]

64. Toh Y, Pencil SD, Nicolson GL. A novel candidate metastasis-associated gene, mta1, differentially expressed in highly metastatic mammary adenocarcinoma cell lines. cDNA cloning, expression, and protein analyses. J Biol Chem. 1994; 269:22958-63. [PubMed: 8083195] 
65. Armache KJ, Garlick JD, Canzio D, Narlikar GJ, Kingston RE. Structural basis of silencing: Sir3 BAH domain in complex with a nucleosome at 3.0 A resolution. Science. 2011; 334:977-82. [PubMed: 22096199]

66. Horton JR, Elgar SJ, Khan SI, Zhang X, Wade PA, Cheng X. Structure of the SANT domain from the Xenopus chromatin remodeling factor ISWI. Proteins. 2007; 67:1198-202. [PubMed: 17377988]

67. Liew CK, Simpson RJ, Kwan AH, Crofts LA, Loughlin FE, Matthews JM, Crossley M, Mackay JP. Zinc fingers as protein recognition motifs: structural basis for the GATA-1/friend of GATA interaction. Proc Natl Acad Sci U S A. 2005; 102:583-8. [PubMed: 15644435]

68. Fujita N, Jaye DL, Geigerman C, Akyildiz A, Mooney MR, Boss JM, Wade PA. MTA3 and the Mi-2/NuRD complex regulate cell fate during B lymphocyte differentiation. Cell. 2004; 119:7586. [PubMed: 15454082]

69. Cismasiu VB, Adamo K, Gecewicz J, Duque J, Lin Q, Avram D. BCL11B functionally associates with the NuRD complex in T lymphocytes to repress targeted promoter. Oncogene. 2005; 24:6753-64. [PubMed: 16091750]

70. Talukder AH, Mishra SK, Mandal M, Balasenthil S, Mehta S, Sahin AA, Barnes CJ, Kumar R. MTA1 interacts with MAT1, a cyclin-dependent kinase-activating kinase complex ring finger factor, and regulates estrogen receptor transactivation functions. J Biol Chem. 2003; 278:1167685. [PubMed: 12527756]

71. Talukder AH, Gururaj A, Mishra SK, Vadlamudi RK, Kumar R. Metastasis-associated protein 1 interacts with NRIF3, an estrogen-inducible nuclear receptor coregulator. Mol Cell Biol. 2004; 24:6581-91. [PubMed: 15254226]

72. Mishra SK, Mazumdar A, Vadlamudi RK, Li F, Wang RA, Yu W, Jordan VC, Santen RJ, Kumar R. MICoA, a novel metastasis-associated protein 1 (MTA1) interacting protein coactivator, regulates estrogen receptor-alpha transactivation functions. J Biol Chem. 2003; 278:19209-19. [PubMed: 12639951]

73. Singh RR, Barnes CJ, Talukder AH, Fuqua SA, Kumar R. Negative regulation of estrogen receptor alpha transactivation functions by LIM domain only 4 protein. Cancer Res. 2005; 65:10594-601. [PubMed: 16288053]

74. Mazumdar A, Wang RA, Mishra SK, Adam L, Bagheri-Yarmand R, Mandal M, Vadlamudi RK, Kumar R. Transcriptional repression of oestrogen receptor by metastasis-associated protein 1 corepressor. Nat Cell Biol. 2001; 3:30-7. [PubMed: 11146623]

75. Feng Q, Cao R, Xia L, Erdjument-Bromage H, Tempst P, Zhang Y. Identification and functional characterization of the p66/p68 components of the MeCP1 complex. Mol Cell Biol. 2002; 22:53646. [PubMed: 11756549]

76. Gong Z, Brackertz M, Renkawitz R. SUMO modification enhances p66-mediated transcriptional repression of the Mi-2/NuRD complex. Mol Cell Biol. 2006; 26:4519-28. [PubMed: 16738318]

77. Tyler JK, Kadonaga JT. The "dark side" of chromatin remodeling: repressive effects on transcription. Cell. 1999; 99:443-6. [PubMed: 10589670]

78. Mazumdar A, Wang RA, Mishra SK, Adam L, Bagheri-Yarmand R, Mandal M, Vadlamudi RK, Kumar R. Transcriptional repression of oestrogen receptor by metastasis- associated protein 1 corepressor. Nat Cell Biol. 2001; 3:30-7. [PubMed: 11146623]

79. Fujita N, Jaye DL, Kajita M, Geigerman C, Moreno CS, Wade PA. MTA3, a Mi-2/NuRD Complex Subunit, Regulates an Invasive Growth Pathway in Breast Cancer. Cell. 2003; 113:207-19. [PubMed: 12705869]

80. Gao Z, Huang Z, Olivey HE, Gurbuxani S, Crispino JD, Svensson EC. FOG-1-mediated recruitment of $\mathrm{NuRD}$ is required for cell lineage re-enforcement during haematopoiesis. Embo J. 2010; 29:457-68. [PubMed: 20010697]

81. Gao H, Lukin K, Ramirez J, Fields S, Lopez D, Hagman J. Opposing effects of SWI/SNF and Mi-2/NuRD chromatin remodeling complexes on epigenetic reprogramming by EBF and Pax5. Proc Natl Acad Sci U S A. 2009; 106:11258-63. [PubMed: 19549820]

82. Cismasiu VB, Paskaleva E, Suman Daya S, Canki M, Duus K, Avram D. BCL11B is a general transcriptional repressor of the HIV-1 long terminal repeat in T lymphocytes through recruitment of the NuRD complex. Virology. 2008; 380:173-81. [PubMed: 18768194] 
83. Nishioka K, Chuikov S, Sarma K, Erdjument-Bromage H, Allis CD, Tempst P, Reinberg D. Set9, a novel histone $\mathrm{H} 3$ methyltransferase that facilitates transcription by precluding histone tail modifications required for heterochromatin formation. Genes Dev. 2002; 16:479-89. [PubMed: 11850410]

84. Zegerman P, Canas B, Pappin D, Kouzarides T. Histone H3 lysine 4 methylation disrupts binding of nucleosome remodeling and deacetylase (NuRD) repressor complex. J Biol Chem. 2002; 277:11621-4. [PubMed: 11850414]

85. Williams CJ, Naito T, Arco PG, Seavitt JR, Cashman SM, De Souza B, Qi X, Keables P, Von Andrian UH, Georgopoulos K. The chromatin remodeler Mi-2beta is required for CD4 expression and T cell development. Immunity. 2004; 20:719-33. [PubMed: 15189737]

86. Yoshida T, Hazan I, Zhang J, Ng SY, Naito T, Snippert HJ, Heller EJ, Qi X, Lawton LN, Williams CJ, Georgopoulos K. The role of the chromatin remodeler Mi-2beta in hematopoietic stem cell self-renewal and multilineage differentiation. Genes Dev. 2008; 22:1174-89. [PubMed: 18451107]

87. Kaji K, Caballero IM, MacLeod R, Nichols J, Wilson VA, Hendrich B. The NuRD component Mbd3 is required for pluripotency of embryonic stem cells. Nat Cell Biol. 2006; 8:285-92. [PubMed: 16462733]

88. Reynolds N, Latos P, Hynes-Allen A, Loos R, Leaford D, O’Shaughnessy A, Mosaku O, Signolet J, Brennecke P, Kalkan T, Costello I, Humphreys P, Mansfield W, Nakagawa K, Strouboulis J, Behrens A, Bertone P, Hendrich B. NuRD suppresses pluripotency gene expression to promote transcriptional heterogeneity and lineage commitment. Cell Stem Cell. 2012; 10:583-94. [PubMed: 22560079]

89. Whyte WA, Bilodeau S, Orlando DA, Hoke HA, Frampton GM, Foster CT, Cowley SM, Young RA. Enhancer decommissioning by LSD1 during embryonic stem cell differentiation. Nature. 2012; 482:221-5. [PubMed: 22297846]

90. Yildirim O, Li R, Hung JH, Chen PB, Dong X, Ee LS, Weng Z, Rando OJ, Fazzio TG. Mbd3/ NURD complex regulates expression of 5-hydroxymethylcytosine marked genes in embryonic stem cells. Cell. 2012; 147:1498-510. [PubMed: 22196727]

91. Covault J, Chalkley R. The identification of distinct populations of acetylated histone. J Biol Chem. 1980; 255:9110-6. [PubMed: 7410415]

92. Nelson D, Covault J, Chalkley R. Segregation of rapidly acetylated histones into a chromatin fraction released from intact nuclei by the action of micrococcal nuclease. Nucleic Acids Res. 1980; 8:1745-63. [PubMed: 7433128]

93. Hu G, Wade PA. NuRD and pluripotency: a complex balancing act. Cell Stem Cell. 2012; 10:497503. [PubMed: 22560073]

94. Smeenk G, Wiegant WW, Vrolijk H, Solari AP, Pastink A, van Attikum H. The NuRD chromatinremodeling complex regulates signaling and repair of DNA damage. The Journal of cell biology. 2010; 190:741-9. [PubMed: 20805320]

95. Li DQ, Ohshiro K, Reddy SD, Pakala SB, Lee MH, Zhang Y, Rayala SK, Kumar R. E3 ubiquitin ligase COP1 regulates the stability and functions of MTA1. Proc Natl Acad Sci U S A. 2009; 106:17493-8. [PubMed: 19805145]

96. Polo SE, Kaidi A, Baskcomb L, Galanty Y, Jackson SP. Regulation of DNA-damage responses and cell-cycle progression by the chromatin remodelling factor CHD4. The EMBO journal. 2010; 29:3130-9. [PubMed: 20693977]

97. Chou DM, Adamson B, Dephoure NE, Tan X, Nottke AC, Hurov KE, Gygi SP, Colaiacovo MP, Elledge SJ. A chromatin localization screen reveals poly (ADP ribose)-regulated recruitment of the repressive polycomb and NuRD complexes to sites of DNA damage. Proceedings of the National Academy of Sciences of the United States of America. 2010; 107:18475-80. [PubMed: 20937877]

98. Larsen DH, Poinsignon C, Gudjonsson T, Dinant C, Payne MR, Hari FJ, Rendtlew Danielsen JM, Menard P, Sand JC, Stucki M, Lukas C, Bartek J, Andersen JS, Lukas J. The chromatinremodeling factor CHD4 coordinates signaling and repair after DNA damage. The Journal of cell biology. 2010; 190:731-40. [PubMed: 20805324] 
99. Helbling Chadwick L, Chadwick BP, Jaye DL, Wade PA. The Mi-2/NuRD complex associates with pericentromeric heterochromatin during $\mathrm{S}$ phase in rapidly proliferating lymphoid cells. Chromosoma. 2009; 118:445-57. [PubMed: 19296121]

100. Sims JK, Wade PA. Mi-2/NuRD complex function is required for normal S phase progression and assembly of pericentric heterochromatin. Molecular biology of the cell. 2011; 22:3094-102. [PubMed: 21737684]

101. Fasulo B, Deuring R, Murawska M, Gause M, Dorighi KM, Schaaf CA, Dorsett D, Brehm A, Tamkun JW. The Drosophila MI-2 chromatin-remodeling factor regulates higher-order chromatin structure and cohesin dynamics in vivo. PLoS genetics. 2012; 8:e1002878. [PubMed: 22912596]

102. Casciola-Rosen L, Mammen AL. Myositis autoantibodies. Curr Opin Rheumatol. 2012; 24:6028. [PubMed: 22955022]

103. Casciola-Rosen L, Nagaraju K, Plotz P, Wang K, Levine S, Gabrielson E, Corse A, Rosen A. Enhanced autoantigen expression in regenerating muscle cells in idiopathic inflammatory myopathy. J Exp Med. 2005; 201:591-601. [PubMed: 15728237]

104. Mammen AL, Casciola-Rosen LA, Hall JC, Christopher-Stine L, Corse AM, Rosen A. Expression of the dermatomyositis autoantigen Mi-2 in regenerating muscle. Arthritis Rheum. 2009; 60:3784-93. [PubMed: 19950298]

105. Pegoraro G, Kubben N, Wickert U, Gohler H, Hoffmann K, Misteli T. Ageing-related chromatin defects through loss of the NURD complex. Nat Cell Biol. 2009; 11:1261-7. [PubMed: 19734887] 


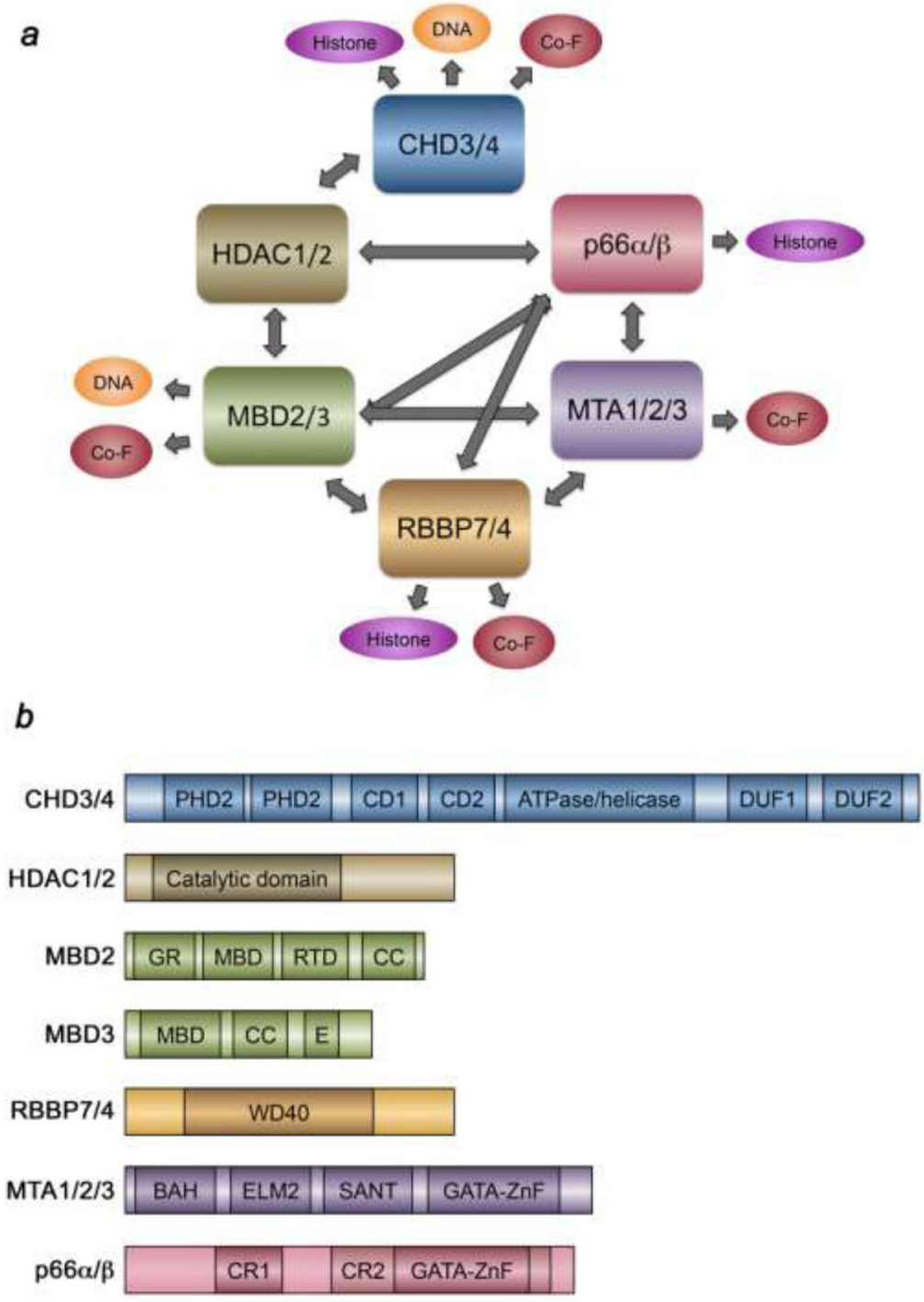

Figure 1. The NuRD complex and its core components

(a) Interactions between subunits and binding of the individual subunits to histones, DNA and other proteins or cofactors (Co-F). Co-F of CHD3/4: hunchback, Tramtrack69, KAP1, NAB2, RFP, E7, RORy, Ikaros, Ki-1/57 and CGI-55; of MBD2: MIZF and FAK; of RBBP7/4: FOG-1, BCL11B and BRCA1; of MTA: BCL-6, BCL11B, oestrogen receptor a, NRIF3, MAT1, MICoA, LMO4 and FOG-1. (b) Domain architecture of each subunit. 


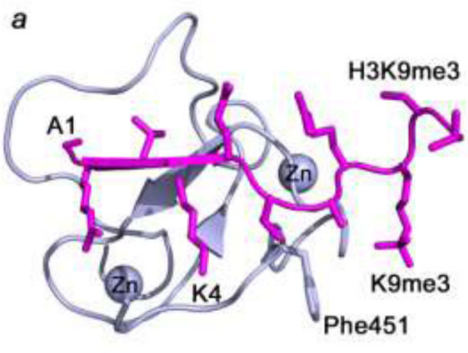

CHD4 PHD2-H3K9me3

$b$

$c$

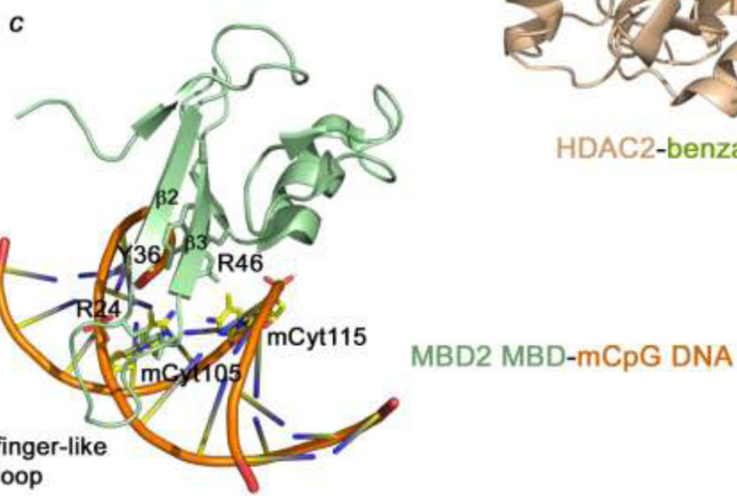

Figure 2. The structural basis for ligand binding by the NuRD components CHD4, HDAC2 and MBD2

(a) Solution structure of the CHD4 PHD2 finger in complex with a H3K9me3 peptide (PDB: 2L75). (b) Crystal structure of HDAC2 in complex with a small molecule inhibitor N-(4aminobiphenyl-3-yl)benzamide (PDB: 3MAX). (c) Solution structure of the MBD module of MBD2 bound to a methylated DNA fragment, derived from the $\rho$-globin promoter (PDB: 2KY8). 

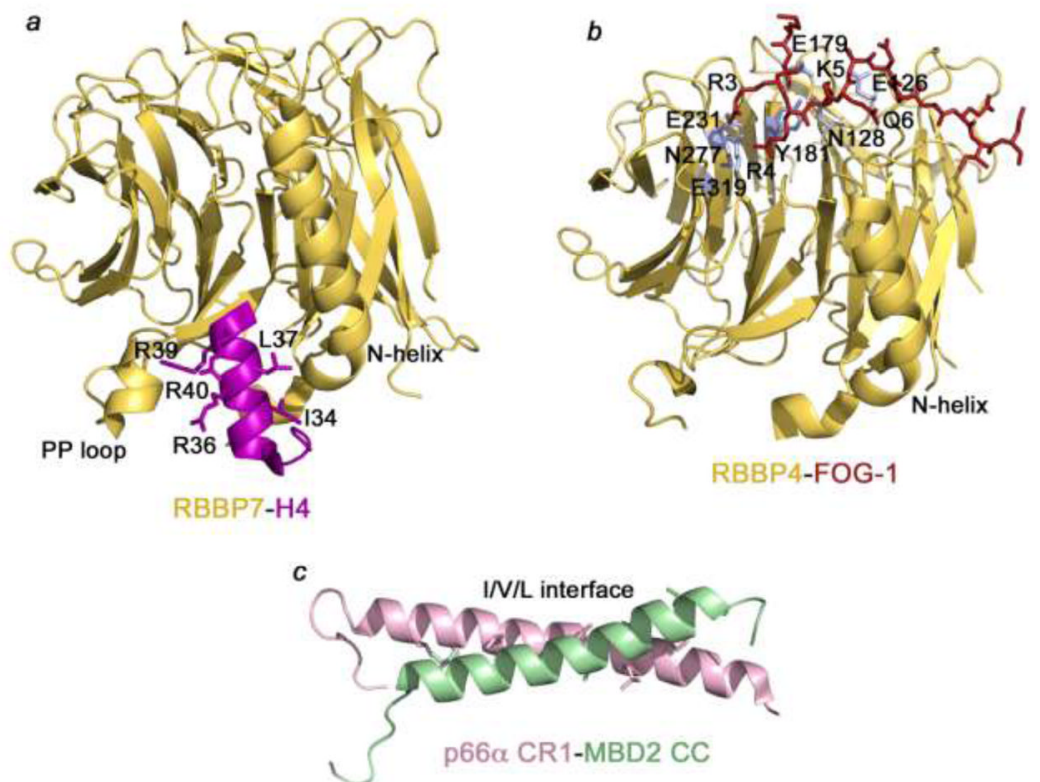

Figure 3. The structural basis for ligand binding by the NuRD components RBBP7/4 and p66a (a) Crystal structure of RBBP7 in complex with a H4 peptide (PDB: 3CFS). (b) Crystal structure of RBBP4 in complex with a FOG-1 peptide (PDB: 2XU7). (c) Solution structure of CR1 of p66a bound to the CC domain of MBD2 (PDB: 2L2L). Hydrophobic Ile, Val and Leu residues forming the coiled-coil interface are shown. 


\section{a}

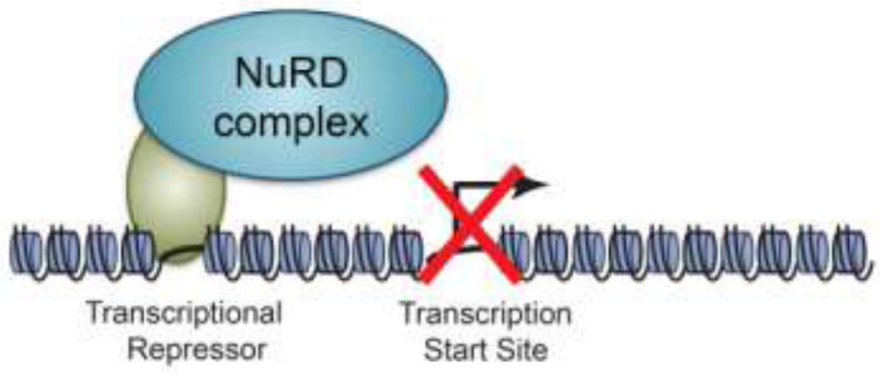

b

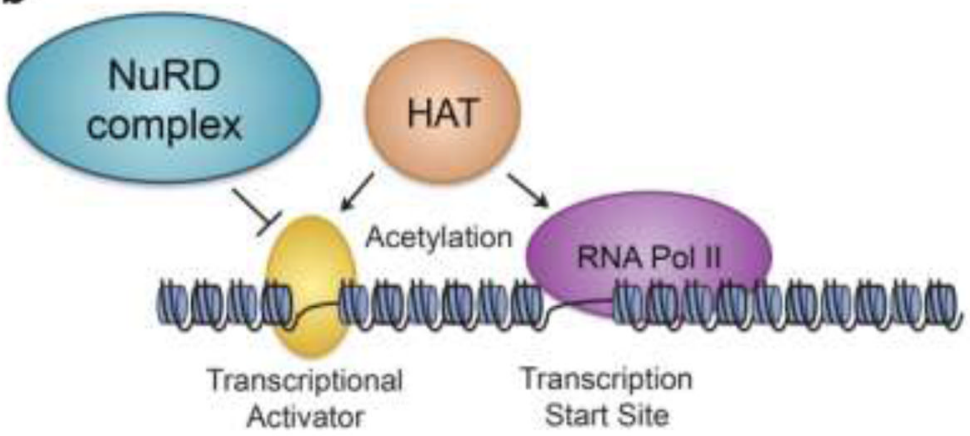

Figure 4. Models depicting NuRD complex recruitment and function

(a) The classic, static model of NuRD action shows association of the NuRD complex with inactive genes. Recruitment is typically depicted as resulting from direct interaction between a NuRD subunit and a transcriptional repressor. (b) A dynamic model for NuRD function shows NuRD as acting to maintain dynamic equilibrium of histone acetylation at an active gene, resulting in fine-tuning of gene expression. 